\title{
LIFETIME ESTIMATE OF PIPE SYSTEMS
}

UDC: 624.042 .62

Original scientific paper

https://doi.org/10.18485/aeletters.2018.3.1.3

\author{
Samir Dizdar ${ }^{1}$, Radoslav Tomović ${ }^{2}$, Adisa Vučina ${ }^{3}$ \\ ${ }^{1}$ BerDiz Consulting AB, Gothenburg, Sweden \\ ${ }^{2}$ University of Montenegro, Faculty of Mechanical Engineering, Podgorica, Montenegro \\ ${ }^{3}$ University of Mostar, Faculty of Mechanical Engineering and Computing, Bosnia and Herzegovina
}

\begin{abstract}
:
Micro cracks have been found near some of the welds on the pipe unit. This paper investigates the root cause of this damage and suggests improvements to prevent such damage from occurring.

The investigation includes several simulations using Pipestress and Ansys Mechanical, a welding and materials investigation, and a more theoretical creep investigation using the Larson-Miller parameter. A sensitivity study of the outlet pigtail installation and support configuration is performed as well as a cyclic plastic analysis. A complementary analysis of the catalyst tubes, inlet and outlet system shows that the only areas where the stress and strain indicate an elevated risk of damage are the areas around the ends of the outlet pigtails.

Suggested improvements include reconfiguration and load reduction of constant hanger supports, improving welding procedures in order to lower residual stresses and undertake more material and on site investigations to verify causes of failure.
\end{abstract}

\section{ARTICLE HISTORY}

Received 04.01.2018

Accepted 22.02.2018

Available 15.03.2018

\section{KEYWORDS}

Cracks, creep, fatigue, plastic analysis, lifetime.

\section{INTRODUCTION}

In a refinery in Norway where a new pipe system was installed, they had serious problems with cracks already after less than a year in use. It is very rare to have similar problems after such a short period of time.

Micro cracks have been found on several of the pipes in the pipe unit [1]. To continue to operate, the root cause need to be determined and potential actions need to be taken.

The purpose of this paper is to analyze the micro cracks in the outlet system and try to establish a root cause for this damage, as well as suggesting how to avoid further damage or prevent such damage in future installations. In addition, a complimentary evaluation is presented in Section 4.

\section{OBJECTIVE AND SCOPE}

The scope of this paper contains an investigation into different damage mechanisms such as creep, fatigue and welding procedure to find a root cause for the micro cracks. An investigation into the previously made calculations is made to establish weather this damage could have been predicted. Using the results of the different analyses, suggestions on improvements are made.

This paper treats the most highly stressed areas and where the damages have been observed. Hence, not all parts of the system are evaluated in detail. The focus lies on the parts containing the welds where micro crack damages have been found, in particular three locations where the most severe damages are observed. Following the notation of [1], these three welds are called S3, S4 and S7. Their locations are shown in Fig.1. 
Several different methods are used to try to determine the cause of the observed damages. The system is investigated with numerical finite element (FE) analyses as well as with analytical and theoretical methods. Welding and inspection books are studied to analyze the choice of materials and welding procedure. The different methods are meant to provide a substantial width in the investigation and hopefully increase the understanding and to prevent damages like these from occurring in the future.

The system is evaluated according to the ASME B31.3 standards [2]. API papers are also considered. ASME B31.3 is used for process piping and will be used to evaluate stresses in the system for design purposes. A Swedish code BSV97 [3] is used for calculation of wind and snow loads on different structures.

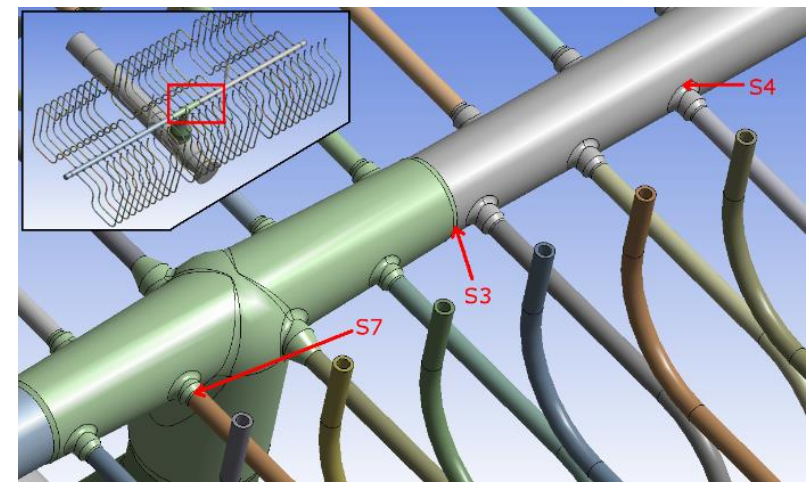

Fig.1. The location of the three most severe damages, (the damages at S3, S4 and S7 are all located on the southern side of the mid-section of the manifold)

\subsection{Pipestress analysis}

The software Pipestress [4] is used to make a model of the piping system and to obtain loads and movements at different points throughout the system.

Pipestress is a one dimensional software that is used to model large piping systems including supports of different kinds. The software is very efficient at calculating the response of the system to different loads and thereby identifying weak points in its design. It is also very useful when wanting to investigate different design solutions.

\subsection{ANSYS finite element analysis}

The software ANSYS Mechanical [5] is used as a verification of the Pipestress results as well as to provide detailed results regarding stress concentrations and stress directions at points of interest. Furthermore, thermal transients and effects due to creep properties of the material are investigated using ANSYS.

\subsection{Loads}

The system is evaluated for sustained loads and thermal range loads. The sustained loads considered are internal pressure and dead weight. The loads are evaluated in accordance with reference [2]. No wind loads have been applied in the calculation, but recorded data suggest that the contribution is small. The temperatures $(T)$ and pressure for the different parts of the system, according to specifications, are presented in Table 1.

Table 1. Temperature and Pressure conditions according to specifications

\begin{tabular}{|l|c|c|c|c|}
\hline \multirow{2}{*}{ Part } & \multicolumn{2}{c|}{ Design } & \multicolumn{2}{c|}{ Operation } \\
\cline { 2 - 5 } & Temperature $\left[{ }^{\circ} \mathrm{C}\right]$ & Pressure [MPa] & Temperature [ ${ }^{\circ} \mathrm{C}$ ] & Pressure [MPa] \\
\hline Transfer Line & 300 & 2.8 & 250 & 2.48 \\
\hline Manifold (Sub Header) & 890 & 2.8 & 860 & 2.48 \\
\hline Pig Tails & 890 & 2.8 & 860 & 2.48 \\
\hline
\end{tabular}

The load combinations are presented in Table 2. Thermal range is the load resulting from Thermal Expansion (TE). Thermal Range is defined as the difference between the cold and hot states of the system. In these cases, Dead Weight (DW) is included together with TE.
Table 2. Load Cases

\begin{tabular}{|c|c|c|}
\hline Load case & Loads & Allowed stress \\
\hline Sustained Loads & DW+DP & SA (from table) \\
\hline Thermal Range & TE (+DW) & SA=1.25 Sc+0.25 Sh \\
\hline Sustained Loads & DW+OP & SA (from table) \\
\hline Thermal Range & TE (+DW) & SA=1.25 Sc+0.25 Sh \\
\hline Combined (Creep) & DW+OP+TE & - \\
\hline
\end{tabular}




\subsection{Welding and materials investigation}

An investigation into what impact welding procedure and material quality may have had on the occurrence of damages is made using installation and inspection books together with comparisons with literature.

The materials used for the different parts are shown in Table 3.

Table 3. Parts and Materials

\begin{tabular}{|c|c|c|c|c|c|}
\hline Part & Material & $\begin{array}{c}\text { Temperature } \\
{\left[{ }^{\circ} \mathrm{C}\right]}\end{array}$ & $\begin{array}{c}\text { Allowable } \\
\text { Stress [MPa] }\end{array}$ & $\begin{array}{c}\text { Young's } \\
\text { Modulus [GPa] }\end{array}$ & $\begin{array}{l}\text { Thermal Expansion } \\
\text { Coefficient }[\mathrm{mm} / \mathrm{m}]\end{array}$ \\
\hline \multirow{3}{*}{ Transfer Line } & \multirow{3}{*}{ A 387 GR. 11 CL. 2} & 20 & 172 & 204 & 0 \\
\hline & & 250 & 130 & 190 & 2.6 \\
\hline & & 300 & 125 & 186 & 3.8 \\
\hline \multirow{3}{*}{$\begin{array}{c}\text { Manifold } \\
\text { (Sub Header) }\end{array}$} & \multirow{3}{*}{ PARALLOY CR32W } & 20 & 116.7 & 196 & 0 \\
\hline & & 860 & 15.18 & 143 & 15.54 \\
\hline & & 890 & 12.64 & 141 & 16.1 \\
\hline \multirow{3}{*}{ Pig Tails } & \multirow{3}{*}{ ASTM B 407 N08811 } & 20 & 115 & 196 & 0 \\
\hline & & 860 & 9 & 143 & 15.35 \\
\hline & & 890 & 6.9 & 141 & 15.59 \\
\hline
\end{tabular}

\section{RESULTS}

Many of the results are presented with the term utilization. The utilization for a component is the fraction between the actual and allowed stress,

$$
\mathrm{U}=\mathrm{S} \_ \text {actual/S_allowed. }
$$

A utilization below $1(U<1)$ means the component is qualified, a utilization above $1(U>$ 1 ) means that a more detailed analysis needs to be performed or requires a change in design.

\subsection{Pipestress Results}

Results are presented for Sustained Loads and Thermal Range Loads with utilization in accordance with ASME B31.3 302.3.5 (c) and (d) [2]. The load cases considered are the conditions for design and operation. Temperature and pressure conditions according to specifications are given in Table 1 and utilizations for the different load cases for the different models are given in Table 4. The model of the current state of the system is also run with the sliding boundary condition at the top of the Pig Tails.

Table 5 shows the stresses at the welds S4, S7 described in the Technical report, reference [1], as well as the stress at the node with highest utilization in the model. The pressure causes a stress of $1.68 \mathrm{MPa}$ in design and $1.48 \mathrm{MPa}$ during operation conditions. Adding the moment stress gives the total sustained stress presented in the table.

Table 4. Utilization

\begin{tabular}{|l|c|c|c|c|}
\hline \multirow{2}{*}{\multicolumn{1}{|c|}{ Part }} & \multicolumn{2}{c|}{ Design } & \multicolumn{2}{c|}{ Operation } \\
\cline { 2 - 5 } & Sustained & Thermal Range & Sustained & Thermal Range \\
\hline Current State & 1.36 & 0.90 & 1.02 & 0.83 \\
\hline C.S. Sliding & & 0.82 & & 0.77 \\
\hline Improved State & 0.84 & 0.90 & 0.63 & 0.83 \\
\hline
\end{tabular}

Table 5. Stresses at S4, S7 and the highest utilization stress MPa, (the node number where the stress occurs in Pipestress is presented in parenthesis)

\begin{tabular}{|c|c|c|c|c|c|}
\hline \multirow{2}{*}{ Part } & \multirow{2}{*}{ Stress } & \multicolumn{2}{|c|}{ Design stress [MPa] } & \multicolumn{2}{|c|}{ Operation stress [MPa] } \\
\hline & & Sustained & Thermal Range & Sustained & Thermal Range \\
\hline \multirow{3}{*}{$\begin{array}{c}\text { Current } \\
\text { State }\end{array}$} & Maximum & 9.36 (PO3L) & 130.4 (PJ27) & 9.16 (PO3L) & 120.4 (PJ27) \\
\hline & S4 (S518-PD10) & 7.45 & 110.2 & 7.25 & 104.4 \\
\hline & S7 (S004-PE30) & 7.39 & 117.1 & 7.19 & 110.7 \\
\hline \multirow{3}{*}{$\begin{array}{l}\text { Current } \\
\text { State } \\
\text { (Sliding) }\end{array}$} & Maximum & 11.64 (PM1L) & 119.1 (S002) & 11.45 (PM1L) & 112.5 (S002) \\
\hline & S4 (S518-PD10) & 7.46 & 108.3 & 7.26 & 102.5 \\
\hline & S7 (S004-PE30) & 7.4 & 118.7 & 7.2 & 112.1 \\
\hline \multirow{3}{*}{$\begin{array}{c}\text { Improved } \\
\text { State }\end{array}$} & Maximum & $5.76(\mathrm{PQ82})$ & 130.4 (PJ27) & 9.49 (SSO2) & 120.4 (PJ27) \\
\hline & S4 (S518-PD10) & 4.17 & 110.2 & 3.97 & 104.4 \\
\hline & S7 (S004-PE30) & 3.88 & 117.1 & 3.68 & 110.7 \\
\hline
\end{tabular}




\subsection{ANSYS results}

Overall, the ANSYS results are in good agreement with the Pipestress results. However, more details are modeled in ANSYS, which results in stress concentrations and higher peak stresses. Another fundamental difference from the Pipestress results is that circumferential stresses due to inner pressure is included in the ANSYS results. The absence of these stresses in Pipestress is a result of Pipestress only being concerned with evaluating longitudinal stresses.

Three different types of analyses are performed with ANSYS:

1. Static structural analyses of the sustained (pressure + dead weight) loads and the thermal expansion load (including dead weight)

2. Creep analyses, to study the creep strain over time at different temperatures.

3. Thermal transient analyses, to study the temperature and local thermal stress distributions at start-ups, shut-downs and trips.

The maximum stresses observed in the considered system parts for the static structural and thermal transient analyses are summarized in Table 6 for the respective load cases. The stresses on the inside and outside of the pipes are presented separately. The internal pressure has little effect on the outside but may cause high stresses on the inside while the dead weight typically affects the outside most. The von Mises stress on the inside and outside surface of a section of the manifold is plotted in Fig.2. One may note in Table 6 and Fig. 2 that the stress under sustained loads is significant on the inside. This occurs on the inside of the manifold at the pig tail connection.

One may also in Table 6 note the large stress due to thermal expansion. This stress arises at the end of the pig tails by the manifold and is considered in detail in the context of the observed damage at the S7 weld.
Table 6. Load Cases

\begin{tabular}{|c|c|c|c|}
\hline & \multirow{2}{*}{$\begin{array}{l}\text { Current load } \\
\text { cases }\end{array}$} & \multicolumn{2}{|c|}{$\begin{array}{l}\text { Maximum stress } \\
{[\mathrm{MPa}]}\end{array}$} \\
\hline & & Inside & Outside \\
\hline \multirow[b]{2}{*}{ Design } & $\begin{array}{l}\text { Sustained } \\
\text { (PD+DW) }\end{array}$ & 36 & 13 \\
\hline & $\begin{array}{c}\text { Thermal } \\
\text { expansion } \\
\left(\mathrm{TE}_{\left.890^{\circ} \mathrm{C}+\mathrm{DW}\right)}\right.\end{array}$ & 75 & 150 \\
\hline \multirow[b]{2}{*}{ Operation } & $\begin{array}{l}\text { Sustained } \\
(\text { PO+DW) }\end{array}$ & 32 & 12 \\
\hline & $\begin{array}{c}\text { Thermal } \\
\text { expansion } \\
\left(\mathrm{TE}_{820}{ }^{\circ} \mathrm{C}+\mathrm{DW}\right)\end{array}$ & 70 & 137 \\
\hline \multirow{2}{*}{$\begin{array}{l}\text { Thermal } \\
\text { Transient }\end{array}$} & $\begin{array}{c}\text { Increasing } \\
(860-20)^{\circ} \mathrm{C} / 4 \mathrm{~h}\end{array}$ & 40 & 25 \\
\hline & $\begin{array}{c}\text { Decreasing } \\
(20-860)^{\circ} \mathrm{C} / 4 \mathrm{~h}\end{array}$ & 130 & 60 \\
\hline
\end{tabular}
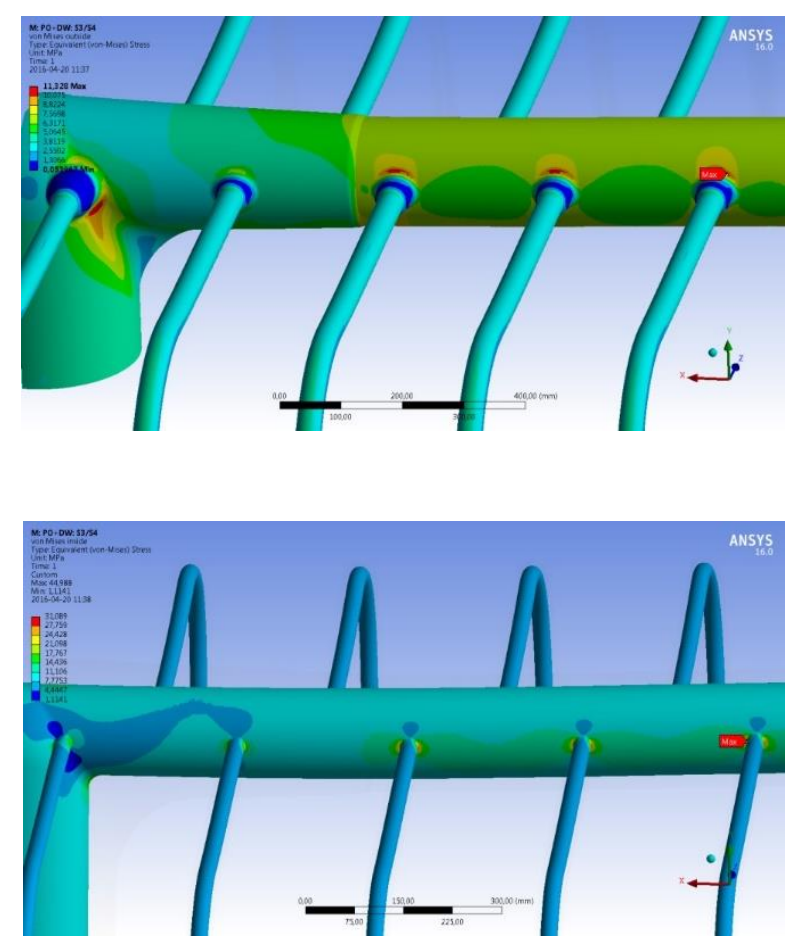

Fig.2. The von Mises stress on a section of the manifold's outer surface (top) and its inner surface (bottom) under PO+DW loads, (the central southern pig tail group is on the bottom of the plots and thus S4 is where the maximum is labelled)

The main results concern the observed damages at S3, S4 and S7. An overview of the maximum principal stresses at these points for different load cases is presented in Table 7, where also the maximum utilization among the points is given for each load case. 
Table 7. Overview of the maximum principal stress, which roughly coincides with the longitudinal direction, at the areas around the observed damages

\begin{tabular}{|c|c|c|c|c|c|c|}
\hline & \multirow[t]{2}{*}{ Current load cases } & \multicolumn{3}{|c|}{$\begin{array}{c}\text { Maximum Principal stress } \\
\text { (Longitudinal) [MPa] }\end{array}$} & \multicolumn{2}{|r|}{ Utilization } \\
\hline & & S3 & S4 & S7 & Overall & Stress limit [MPa] \\
\hline \multirow[t]{3}{*}{ Design } & Sustained (PD+DW) & $7.5^{*}$ & 14.7 & 7 & 1.16 & 12.64 \\
\hline & Thermal expansion $\left(\mathrm{TE}_{890^{\circ} \mathrm{C}}+\mathrm{DW}\right)$ & 20 & 63 & 175 & - & - \\
\hline & Thermal range $\left(890-20^{\circ} \mathrm{C}\right)$ & 14 & 50 & 168 & 1.15 & 145.5 \\
\hline \multirow[t]{3}{*}{ Operation } & Sustained (PO+DW) & $8.5^{*}$ & 13.3 & 7 & 0.88 & $15.18^{* *}$ \\
\hline & Thermal expansion $\left(\mathrm{TE}_{\left.820^{\circ} \mathrm{C}+\mathrm{DW}\right)}\right.$ & 19 & 54 & 158 & - & - \\
\hline & Thermal Range $\left(820-20^{\circ} \mathrm{C}\right)$ & 13 & 41 & 151 & 0.98 & 154 \\
\hline
\end{tabular}

The non-linear behavior of creep makes the results from the creep analyses very sensitive to the particular values used for the temperature and material properties. Thus, the creep results are here chosen to be summarized with a plot rather than a table. In this way, one may judge the behavior of the creep in the model. One of the locations found to be quite sensitive to creep is the upper part of the weld between manifold and pig tail weldolets, e.g. where the damage at S4 where found. The strain at such a point is plotted against time for various temperatures in Fig.3. The strong temperature dependence is evident from the plot where it can be seen that changing the temperature from 820 to $860{ }^{\circ} \mathrm{C}$ reduces the time to reach a particular strain almost by a factor of 10 .

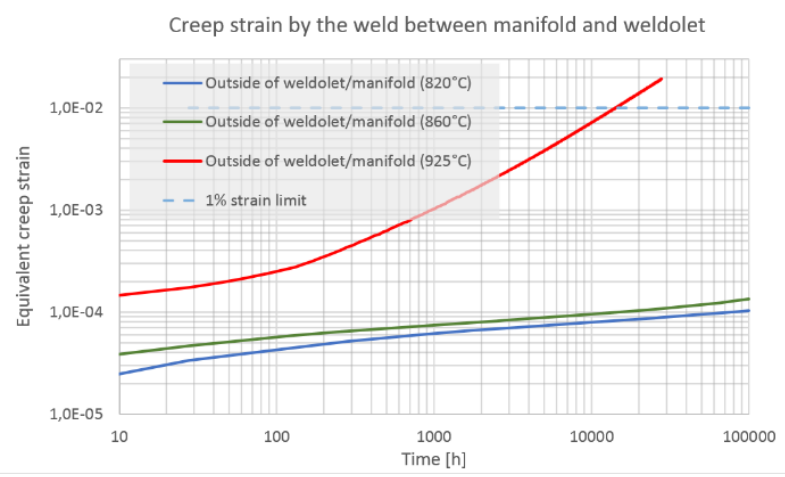

Fig.3. The strain over time at the weld between manifold and weldolet, e.g. S4's location, (the $1 \%$ strain limit at which creep damages might emerge is plotted as a dashed line)

The outside of weldolet/manifold was one of the most highly stressed points under sustained loads, which is why it is susceptible to creep. The point on the inside, mentioned earlier, where the maximum stress occurs during sustained loads, is located on the inside of the manifold by the pig tail connection. Due to its higher stress, this point is even more susceptible to creep. Therefore, creep damages might be worse on the inside and it is not unlikely that micro cracks also could be found on the inside of the manifold.

The following list summarizes the conclusions which can be drawn from the ANSYS results regarding the damages at S3, S4 and S7.

S3: The evaluated stresses around S3 for the different load cases do not on their own suggest that there would be any damages there at this time nor in the near future. Perhaps together with the residual stresses, discussed in the next section, they could contribute to damages.

S4: The stresses due to sustained loads around S4 exceed the allowed limit in the design case and are highly utilized in the operational case. However, the region is shown to be sensitive to creep strain but with current data it is difficult to make accurate predictions regarding its life time. Furthermore, the thermal stress range is moderate and fatigue will thus give negligible contributions.

S7: The thermal stress range at this weld is large but lie $2 \%$ below the allowed limit in the operational case. However, this limit is rather conservative, in particular in this case where the actual number of cycles is so small. Furthermore, a comparison of the strain range with the low-cycle fatigue data of the similar INCOLOY $800 \mathrm{H}$ alloy [6] shows that the evaluated strain is roughly 50 times smaller than that which would cause failure.

Even though the magnitude of the evaluated stresses at the damaged regions do not provide striking, conclusive evidence of the cause of micro cracks, their directions correspond well with the orientation of the cracks. The number of tests and observed cracks do not provide a good statistical basis but there seems to be a correlation between the directions of stresses and cracks. This may suggest that the stress have had an impact on the crack formation, perhaps in combination with 
factors not accounted for here, e.g. residual stresses in the welds.

\subsection{Creep Analysis Results}

The evaluated utilization at the current time with regard to expected lifetime varies by use of data from references $[2,6,7]$. The results for the two stresses $10 \mathrm{MPa}$ and $14.7 \mathrm{MPa}$ at different operational temperatures are presented in Table 8 for the different references. The corresponding expected lifetime for these temperatures at the stress of 14.7 MPa is presented in Table 9.

From the results, it is clear that the materials differ in rupture life, with the ASME material being considerably weaker. The ASME material has a safety factor applied to it to get the allowable stress given in the code [2]. This explains most of the difference but since the determining material value is unknown a compensation for the safety factors cannot be made. Furthermore, the ASME material is specified for the weldolets, to which two of the critical welds are connected.

Table 8. Utilization at present time of operation for different operational temperatures

\begin{tabular}{|c|c|c|c|c|c|c|}
\hline \multirow{2}{*}{$\begin{array}{l}\text { Operational } \\
\text { Temperature }\end{array}$} & \multicolumn{2}{|c|}{ PARALLOY, reference [7] } & \multicolumn{2}{c|}{ INCOLOY, reference [5] } & \multicolumn{2}{c|}{ ASME B31.3, reference [2] } \\
\cline { 2 - 7 } & $\mathbf{1 0} \mathbf{M P a}$ & $\mathbf{1 4 . 7} \mathbf{~ M P a}$ & $\mathbf{1 0 ~ M P a}$ & $\mathbf{1 0 ~ M P a}$ & 14.7 MPa & 10 MPa \\
\hline $820^{\circ} \mathrm{C}$ & 0.002 & 0.005 & 0.002 & 0.01 & 0.16 & 0.43 \\
\hline $840^{\circ} \mathrm{C}$ & 0.006 & 0.01 & 0.006 & 0.03 & 0.38 & 0.99 \\
\hline $860^{\circ} \mathrm{C}$ & 0.02 & 0.04 & 0.02 & 0.11 & 0.86 & 2.20 \\
\hline $880^{\circ} \mathrm{C}$ & 0.05 & 0.1 & 0.07 & 0.35 & 1.89 & 4.75 \\
\hline
\end{tabular}

Table 9. Expected life (rupture life) [h] at constant stress 14.7 MPa

\begin{tabular}{|c|c|c|c|}
\hline \multirow{2}{*}{$\begin{array}{l}\text { Operational } \\
\text { Temperature }\end{array}$} & PARALLOY, reference [7] & INCOLOY, reference [5] & ASME B31.3, reference [2] \\
\cline { 2 - 4 } & $\mathbf{1 4 . 7} \mathbf{~ M P a ~ h}$ & $\mathbf{1 4 . 7} \mathbf{~ M P a}$ & $\mathbf{1 4 . 7} \mathbf{~ M P a}$ \\
\hline $820^{\circ} \mathrm{C}$ & $9610000 \mathrm{~h}$ & $4320000 \mathrm{~h}$ & $100000 \mathrm{~h}$ \\
\hline $840^{\circ} \mathrm{C}$ & $3250000 \mathrm{~h}$ & $1270000 \mathrm{~h}$ & $43700 \mathrm{~h}$ \\
\hline $860^{\circ} \mathrm{C}$ & $1140000 \mathrm{~h}$ & $391000 \mathrm{~h}$ & $19700 \mathrm{~h}$ \\
\hline $880^{\circ} \mathrm{C}$ & $417000 \mathrm{~h}$ & $125000 \mathrm{~h}$ & $9100 \mathrm{~h}$ \\
\hline
\end{tabular}

The contribution from fatigue is very low. Considering that the utilization from fatigue is combined with the utilization from creep as a sum of squares, when the creep-fatigue utilization is evaluated, the contribution from fatigue becomes completely dismissible.

\section{COMPLEMENTARY ANALYSIS OF THE INLET SYSTEM AND CATALYST TUBES}

The additional analysis presented in this section serves as a current status check and verification of the inlet system and catalyst tubes of system. To take into account interactions between the different system parts, the outlet parts are considered in this analysis as well.

The Pipestress software is used to determine the stress levels in the inlet system. Furthermore, Pipestress provides displacement results, which are used as input in the more detailed ANSYS analysis of the Pig Tails and Catalyst Tubes, which also models the development of creep strains in the materials.
The loads considered are the same as for the previous analyses, Dead Weight (DW), Thermal Expansion (TE) and Operational Pressure (OP). The Pipestress analysis evaluates both the Design case as well as the operational conditions while Ansys only considers the operational case. A summary of the temperatures and pressures in the system is presented in Table 10.

Table 10. Load Cases

\begin{tabular}{|c|c|c|c|c|}
\hline \multirow{2}{*}{ Part } & \multicolumn{2}{|c|}{ Design } & \multicolumn{2}{c|}{ Operation } \\
\cline { 2 - 5 } & $\begin{array}{c}\text { Temp. } \\
{\left[{ }^{\circ} \mathrm{C}\right]}\end{array}$ & $\begin{array}{c}\text { Press. } \\
{[\mathrm{MPa}]}\end{array}$ & $\begin{array}{c}\text { Temp. } \\
{\left[{ }^{\circ} \mathrm{C}\right]}\end{array}$ & $\begin{array}{c}\text { Press. } \\
{[\mathrm{MPa}]}\end{array}$ \\
\hline Inlet & 540 & 3.15 & 450 & 2.8 \\
\hline Catalyst & 922 & 2.8 & 880 & 2.48 \\
\hline Outlet & 890 & 2.8 & 860 & 2.48 \\
\hline
\end{tabular}

The results of the Ansys analysis, show that no severe stresses or strains are found in the catalyst tubes or the inlet pigtails. The maximum creep strain in the inlet system is $0.07 \%$ and is not in the vicinity of any weld which might affect crack formation and is thus not considered a risk area. The only significant strain in connection to the 
catalyst tubes is at the bottom of the reducer to the outlet pigtail where comparatively large stresses and creep strains occur. It is at the upper end of the outlet pigtail where the maximum creep strains occur. These are approximately $0.2 \%$ after 100000 $h$, and are at the same levels as at lower end of the pigtail towards the manifold, where cracks have been observed. These creep strain levels are not on their own worrying but taking to account the fact that cracks have been observed at locations showing the same levels of stress and strain in combination with close proximity welds, these are considered risk areas. The areas with elevated risk for damage are encircled in Fig.4.

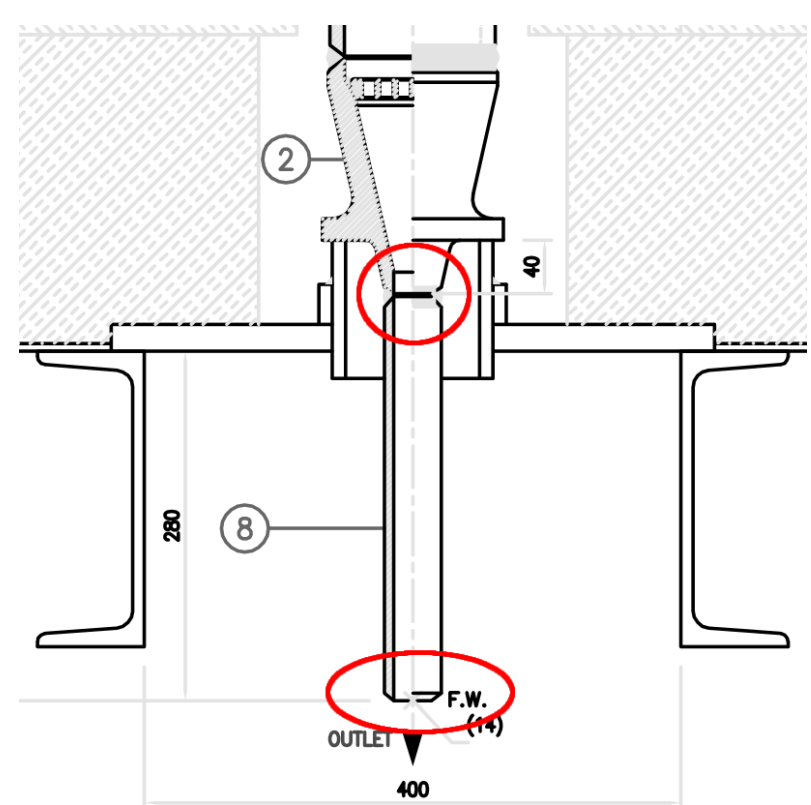

Fig.4. Regions at the upper end of outlet pigtails considered to have an elevated risk of damage

\section{CONCLUSION}

The system seems to have been manufactured and evaluated in accordance with applicable standards and codes, save the questionable existence of an applied wind load, which would not influence the result significantly.

Moving the constant hanger supports according to the improved Pipestress model would greatly reduce the creep driving forces, e.g. sustained loads. The analyses over all shows that the system is very sensitive to the loads from the constant hangers. The movements of the pipes from sustained loads are very small; this indicates that the system is very sensitive to small changes during installation, e.g. mounting of insulation and cladding as well as the relative position on the pipes in relation to the constant hanger support.

The Ansys analysis indicates that creep could be the root cause of the damage at the S4 weld. However, the point most sensitive to creep in the model lies on the inside of the manifold, which suggest that creep damages could be worse there. In general, the observed crack orientations are consistent with the direction of the principal stresses. However, the magnitude of the principal stresses are typically not large enough to, by themselves, be the cause of the observed damages, indicating the presence unknown stresses, for example residual stresses.

The complementary analysis of the inlet system and catalyst tubes show that there are no regions of significant stress or creep strain in these parts. The analysis show that the ends of the outlet pigtails (and adjacent reducer and manifold respectively) acquire the largest creep strains. Because of their similarity (in terms of creep strain, material and close proximity to welds) to the locations where cracks are observed these locations are considered as areas with risk for damage.

\section{REFERENCES}

[1] Teknisk rapport, Replikprovning AG, BerDiz Consulting AB, Rev 01A, 2015.

[2] ASME B31.3, 2012.

[3] Boverket, Boverkets handbook om snö och vindlast, 1997, Boverket $2^{\text {nd }}$ edition. (In Swedish).

[4] DST Computer Services S.A., PIPESTRESS, version 5.0.

[5] ANSYS Mechanical, Release 16.0, ANSYS, Inc.

[6] Catalog: INCOLOY alloy 800T \& 800HT, Special Metals Corporation, 2004.

[7] Catalog: Heat resistant alloy technology centrispun tubes and statically cast fittings, fabricated coils, catalyst tubes and manifolds. DONCASTER PARALLOY, UK.

The shorter version of this research was presented at the "8nd International Scientific Conference IRMES 2017", 7 - 9 September 2017, Trebinje, Bosnia and Hercegovina. 